\title{
Frontiers
}

in the Psychotherapy of Trauma \& Dissociation

\section{The Case of the Shaking Legs: Somatoform Dissociation and Spiritual Struggles \\ Alfonso Martínez-Taboas, Ph.D.}

The Official Clinical Journal of the International Society for the Study of Trauma and Dissociation 


\section{Frontiers in the Psychotherapy of Trauma \& Dissociation}

The Official Clinical Journal of the ISSTD

\section{EDITORS}

A. STEVEN FRANKEL, Ph.D., J.D., Clinical Professor of Psychology, University of Southern California, Los Angeles, California, USA

ANDREAS LADDIS, M.D., Private Practice and Faculty, Boston University, School of Public Health, Boston, Massachusetts, USA

\section{ASSOCIATE EDITOR}

MARTIN J. DORAHY, Ph.D., Professor, Department of Psychology, University of Canterbury, Christchurch, New Zealand and The Cannan Institute, Brisbane, Australia

Frontiers in the Psychotherapy of Trauma E Dissociation is published by the International Society for the Study of Trauma and Dissociation, Inc., 8400 Westpark Drive, 2nd Floor, McLean, Virginia, 22102, USA.

\section{Annual Subscription, Volume 2, 2018}

Online subscription is part of the membership dues of the International Society for the Study of Trauma and Dissociation. Visit http://www.isst-d.org/default.asp?contentID=44.

Production and Advertising Office: ISSTD Headquarters, 8400 Westpark Drive, 2nd Floor, McLean, Virginia, 22102. Attention: Thérèse O. Clemens, CAE, Managing Editor.

Copyright $(2018$ International Society for the Study of Trauma and Dissociation. All rights reserved. No part of this publication may be reproduced, stored, transmitted, or disseminated in any for or by any means without prior written permission from the International Society for the Study of Trauma and Dissociation. The publisher assumes no responsibility for any statements of fact or opinion expressed in the published papers. The appearance of advertising in this journal does not constitute an endorsement or approval by the publisher, the editor, the editorial board, or the board of directors of the International Society for the Study of Trauma and Dissociation of the quality or value of the product advertised or of the claims made of it by its manufacturer.

Subscriptions to this journal are acquired through membership in the International Society for the Study of Trauma and Dissociation only.

Visit http:/ / www.isst-d.org/default.asp?contentID=45.

Permissions. For further information, please write to info@isst-d.org.

\section{EDITORIAL BOARD}

ELIZABETH S. BOWMAN, M.D., Editor Emerita, Journal of Trauma \& Dissociation, Adjunct Professor of Neurology, Indiana University School of Medicine, Indianapolis, Indiana, USA

LAURA S. BROWN, Ph.D., Private Practice, Seattle, Washington, USA

RICHARD A. CHEFETZ, M.D., Private Practice, Faculty and Founding Member Institute of Contemporary Psychotherapy \& Psychoanalysis, Distinguished Visiting Lecturer: William Alanson White Institute of Psychiatry, Psychoanalysis \& Psychology, New York City, USA

CONSTANCE J. DALENBERG, Ph.D., Trauma Research Institute, California School of Professional Psychology, San Diego, California, USA

J.K. JUDITH DANIELS, Ph.D., Faculty of Behavioural and Social Sciences, University of Groningen, The Netherlands

STEVEN N. GOLD, Ph.D., Professor, Center for Psychological Studies, and Founding Director, Trauma Resolution E Integration Program, Nova Southeastern University, Fort Lauderdale, Florida, USA

ELIZABETH B. HEGEMAN, Ph.D., Professor, Department of Anthropology, John Jay College of Criminal Justice, New York, New York, USA 
RICHARD P. KLUFT, M.D., Ph.D., Private Practice and Clinical Professor of Psychiatry, Temple University School of Medicine; Faculty Member, Philadelphia Center for Psychoanalysis, Philadelphia, Pennsylvania, USA

CHRISTA KRÜGER, M.D., Professor of Psychiatry, University of Pretoria, Pretoria, Gauteng, South Africa

KARLEN LYONS-RUTH, Ph.D., Professor of Psychology, Harvard Medical School, Cambridge, Massachusetts, USA

ALFONSO MARTÍNEZ-TABOAS, Ph.D., Professor, Albizu University, San Juan, Puerto Rico WARWICK MIDDLETON, M.D., Adjunct Professor, Cannan Institute, Brisbane, Australia ELLERT R. S. NIJENHUIS, Ph.D., Department of Psychiatry and Outpatient Department Mental Health Care Drenthe, Assen, The Netherlands

SANDRA PAULSEN, Ph.D., Bainbridge Institute for Integrative Psychology, Bainbridge Island, Washington, USA

VEDAT ŞAR, M.D., Professor of Psychiatry, Koç University School of Medicine (KUSOM), Istanbul, Turkey

JOYANNA SILBERG, Ph.D., Trauma Disorders Program, Sheppard Pratt Health Systems, Baltimore, Maryland, USA

KATHY STEELE, M.N., C.S., Private Practice, Atlanta, Georgia, USA

ONNO VAN DER HART, Ph.D., Emeritus Professor of Psychopathology of Chronic Traumatization, Department of Clinical and Health Psychology, Utrecht University, Utrecht, The Netherlands

VICTOR WELZANT, PSY.D., Sheppard Pratt Health Systems, Trauma Disorders Program

\section{REVIEWERS}

JOHN BRIERE, Ph.D., Associate Professor of Psychiatry and Psychology, University of Southern California Keck School of Medicine, Los Angeles, California, USA

SHELDON IZKOWITZ, Ph.D., Clinical Associate Professor of Psychology and Clinical Consultant, Postdoctoral Program, New York University, New York City, USA and Teaching Faculty \& Supervisor of Psychotherapy and Psychoanalysis, National Institute for Psychotherapies, New York City, USA

MARY-ANNE KATE, Ph.D. CANDIDATE, Researcher at University of New England, Australia; University of New England, New South Wales, Australia

ULRICH F. LANIUS, Ph.D., Private Practice, West Vancouver, British Columbia, Canada

\section{SUPPORTERS}

ISSTD thanks its generous supporters whose contributions have made this publication possible:

Andreas Laddis, M.D., USA

\section{The}

\section{Cannan}

\section{Institute}

Cannan Institute, Australia

Warwick Middleton, M.D., Australia

Dana Ross, M.D., Canada

Martin J. Dorahy, Ph.D., New Zealand

Kate McMaugh, Australia

Sara Y. Krakauer, USA 


\title{
ARTICLE \\ The Case of the Shaking Legs: Somatoform Dissociation and Spiritual Struggles
}

\author{
ALFONSO MARTÍNEZ-TABOAS, Ph.D. ${ }^{1}$ \\ Carlos Albizu University
}

Psychogenic non-epileptic seizures (PNES) are episodic behavior that resembles epileptic seizures but without epileptiform activity in the brain. They are expression of psychological conflict. From the perspective of theory, research, and clinical experience, many authors have conceptualized PNES as a kind of somatoform dissociation. This article presents a clinical case study of a young and very religious woman who suffered episodes of marked seizure-like movements in both legs. These episodes began when the time approached to keep her earlier commitment to dedicate herself to a nun's life in a convent. While in psychotherapy, she revealed and deliberated tremendous spiritual struggle about keeping that commitment. She acknowledged great fear of rejection by her church, family and friends, if she chose to pursue, instead, her newfound desire for a mate and a family. Therapy helped Nancy with psychoeducation about PNES, gaining insight about her spiritual conflict, validation of her authentic desires and assertiveness training. It helped her reason with her family and friends for their approval and to begin dating. While taking those steps for resolution of her spiritual conflict and approached termination of therapy, Nancy's episodes of PNES abated steadily. This case study illustrates that dissociative somatoform symptoms are manifestation of powerlessness to cope with grave danger, in Nancy's case, danger of losing relationships she needed to live an authentic life. It also illustrates the effectiveness of psychotherapy that helps end that powerlessness.

\footnotetext{
${ }^{1}$ Correspondence concerning this article should be addressed to Alfonso MartínezTaboas, Ph.D., Carlos Albizu University, Department of Clinical Psychology, 151 Tanca St., San Juan, Puerto Rico. 00901.
} 
KEYWORDS psychogenic non-epileptic seizures; somatoform dissociation; spiritual struggles; psychotherapy

The concept of dissociation, as originally developed by Pierre Janet in the XIX century, encompassed a disaggregation of cognitive and bodily functions from higher volitional intentional actions and consciousness processes. In particular, somatoform dissociation includes disruptions in the integration of perception, sensations, bodily functions, and movement. An early clinical example of somatoform dissociation was reported by Janet. In that case, after having experienced some stressful events as a child and adolescent, Marie developed seizure-like symptoms and blindness in one of her eyes. Those symptoms were representations of her fears that were transformed into bodily dysfunctions (Ellenberger, 1970).

More recently, a group of scholars in the dissociation and trauma field, have reignited interest in the somatic forms of dissociation (Nijenhuis, 2004, 2009). Relevant research indicates that many patients with dissociative disorders also manifest somatoform and conversion symptoms (Brown, 2007). Also, there is usually a strong correlation between dissociative symptoms and conversion disorders (Sar, Akyuz, Kundakci, Kiziltan, \& Dogan, 2004; Yaila, Bakim, Tankaya, Ozer, Karamuztafalioglu, Ertekin \& Tekin, 2015). For that reason, the International Classification of Disease (ICD-10) decided to rename such disorders as "dissociative disorders of movement and disease".

To recognize the importance of somatic disorders in the concept of dissociation, Nijenhuis and colleagues developed the concept of somatoform dissociation and created the Somatoform Dissociation Questionnaire (Nijenhuis, Spinhoven, Van Dyck, Van der Hart \& Vanderlinden, 1996) Research with the SDQ has revealed that somatoform dissociation is associated with psychoform dissociation, suggesting that both share a common underlying process (Nijenhuis, Van der Hart, Kruger \& Steele, 2004).

One specific manifestation that has been thoroughly investigated is Psychogenic-Non-Epileptic Seizures (PNES; LaFrance, \& Schachter, 2018). PNES was a major subject of interest in the 19th century, having attracted the attention of such eminent figures as Charcot, Briquet, and Janet (Trimble, 2010). In PNES the patient typically presents a seizure, whose cause cannot be attributed to epilepsy or other biological dysfunction. Additionally, usually there are evident psychological factors associated with the development of the disorder. A number of studies indicate that many PNES patients present a history of psychological trauma or other types of stressful psychological experiences (Bodde, Van der Kruijs, Lazeron, Vonck, Boon, \& Aldenkamp, 2013; González-Vázquez, Río-Casanova, SeijoAmeneiros, Cabaleiro-Fernández, Seoane-Pillado, Justo-Alonso, \& SanyedGermán, 2017). Also, a considerable number of PNES patients display additional dissociative symptoms or disorders (Pick, Melers \& Goldstein, 2017). 
The following case study of a PNES patient illustrates how conflictual and spiritual struggles result in somatoform dissociate processes that reflect erratic decisions previously taken by the patient. I will also explain how integrative psychotherapy, which included psychoeducation, intrapsychic insight, cognitive reassessment of earlier decisions, and assertiveness training, resulted in dramatic abatement of PNES and in her commitment to a different lifestyle that was more congruent with her life expectations.

\section{THE CASE OF NANCY}

Nancy is a Puerto Rican 21-year-old woman that was referred by her neurologist because of her constant psychogenic seizures. Nancy has a BA in social work, resides with both of her parents, and she describes herself as deeply religious. She describes her religious life and convictions as extremely important for her and her family. In fact, at 18 years of age, she publicly announced to her family and friends that she wanted to become a nun. She reported that she has participated in religious missions in Peru, Colombia, and Guatemala helping poor communities. As part of her plans to be a nun, she has already contacted some convents and has a nun (Anita) designated as her spiritual advisor. In about a year, she is expected to enter a convent in the USA.

She reported that her parents were joyful for her decision to lead a deeply religious life and other family members were also encouraging her decision. When I asked her if she wanted to be a nun, she told me: "That was my decision and all the people that I care and love are expecting this from me."

However, about six months prior to her referral, and shortly after visiting her spiritual advisor in the convent in the USA, Nancy began to suffer involuntary movements in both legs. The movement begins slowly, first in her right leg, then progress to the left one. Subsequently, both legs manifest extreme involuntary movements that impeded her to walk. Those spasmodic movements last around 10 minutes and in the last two months reached a peak with about 15 seizures per month.

The seizures have caused a halt in her life. She was unable to work and had to quit her job at a grocery store. Also, when she informed Anita of the constant seizures, Anita recommended that her priority now should be restoring her health and thus her plans to become a nun came to a halt.

As the seizures were so disturbing, she decided to make an appointment with a neurologist. The first impression of the neurologist was that the seizures could be some type of epilepsy, in particular, simple partial seizures. In such a condition, the patient exhibits some involuntary movements in a particular part of the body. Consciousness usually is not affected, so the patient has a clear memory of the event. Her neurologist recommended an anticonvulsant (Keppra). 
Despite taking the medication, her seizures remained unabated. Two EEGs did not reveal anything unusual, so she was transferred to a unit specializing in epilepsy in Puerto Rico. There she stayed seven days while her seizures were monitored with video-EEG. While in the unit, she suffered several seizures; all located in her lower limbs. The final decision of the neurologist at the specialized unit was that none of the seizures were related to abnormal waves in her brain. The diagnosis was Psychogenic Non-Epileptic Seizures (PNES).

As is so typical in cases of PNES, Nancy has never heard about PNES. She was utterly confused. She asked herself; "What does it means that her seizures were psychological?" How was it possible that her unusual limb movements were produced by some unconscious mental mechanism?

Those were the questions that Nancy pondered at our first session of psychotherapy. I learned that she came from a hard-working family that was also deeply religious. She has been a healthy woman until now, and she has never suffered from any psychiatric problem. Since she had made a pledge with God to be a virgin and to become a nun, so far, she had never had a sexual encounter. Years ago, she had a boyfriend, but she only permitted kisses and some light petting.

Nancy remarked that was satisfied with her social life; she had many friends and a gratifying relationship with her family. In terms of her future plans, she insisted that her number one priority was to become a nun. She already had taken steps toward making her plan a reality.

At that first session, I explained to Nancy that it would be helpful, with her consent, to evaluate her seizures with a hypnotic induction that I have been using for over a decade (see Martínez-Taboas, 2002). I explained to her that the induction was simple; all she had to do was to close her eyes, listen attentively to my voice, and enter an imaginary room where her mind will localize the exact moment of her last seizure. She consented to do the induction in the next session.

In the second session, the induction was completely successful. In less than two minutes both legs began to tremble. First there was a slight movement, but it progressed to the point where both legs began to shake vigorously. Her upper limbs and torso showed no movements and she was completely conscious of what was occurring. After observing the seizure, I commanded with a firm voice that at the count of three the seizure will stop. When I counted three, the unusual movements suddenly receded. This confirmed the diagnosis of Nancy's disorder as PNES (for the role of hypnosis in the assessment and treatment of PNES, see Barry, 2006; Moene \& Kuyk, 2010).

At the third session we began to talk about possible psychological events or conflicts that were contributing to her PNES. Since there is no history of trauma, no unusual problems in her work, her family relations are acceptable, what might explain her PNES? 
When I carefully inquired about her pledge to become a nun, I noted some hesitation. She reluctantly confessed that she has often pondered how she would manage her sexual urges if she became a nun. She acknowledged that she enjoyed to masturbate with some frequency, and to fantasize various sexual scenes that culminated in orgasm. Also, she recognized that she had tremendous curiosity about why so many female friends remarked on the pleasures and satisfactions of being sexually active. She confessed that sometimes she regretted having made the pledge to become a nun. She acknowledged doubts about suffering the restrictions of life in the convent. More importantly, she emphasized her fear that many significant persons in her life (i.e., friends, family, her parents, her religious congregation) would be gravely disappointed if she decided to retract her pledge to become a nun. She feared that many of them could not understand or sympathize with her new reasons, and would not support her in her new future.

At this point, I asked her; "Then, why do you want to commit your life to a lifestyle that maybe is not for you?" Nancy, for the first time, recognized that she had enormous doubts, but that she has proceeded with her plans because many significant people in her life (Anita, her family, friends) would be disappointed if she retracted. To fully understand Nancy's struggle, we must emphasize that the culture in many Latino families is for commitment to keep relationships strong in the nuclear and extended family networks through all life stages. The concept of familismo implies an emphasis on family cohesiveness, loyalty, and responsibility (Falicov, 2014). It was evident, therefore, that Nancy was experiencing a deep spiritual struggle, accompanied with psychological conflicts and suffering (Exline \& Rose, 2013).

\section{THE NEW JOURNEY}

In the next two sessions, and with this new information, Nancy and I began to construct a possible psychological hypothesis to explain her PNES. First, I explained to Nancy the concept of dissociation and specifically of somatoform dissociation. After explaining the concept, I introduced the following clinical hypothesis; the PNES reflected an unconscious conflict about becoming a nun. As she had not expressed and acknowledged verbally her reluctance to become a nun, a part of her was manifesting this conflict and doubts in a somatoform dissociative way. In other words, the shaky legs were an alternative way to express her deep fear of committing her life to a lifestyle that she is now recognizing will be utterly unsatisfying for her.

This clinical hypothesis was validated by Nancy. For the first time in her life, she could verbally express that she did not want to become a nun. We decided to use the next two sessions to evaluate the pros and cons of her new judgment. The results were clear. As a young woman, she wanted definitely to explore heterosexual encounters, discover her sexuality, expand 
her social life, continue her undergraduate studies, and travel the world. As for her religious and spiritual life, she now visualized a continued relationship, but not as a nun, let alone in a convent.

As her psychotherapist, I explored all those subjects with an emphatic stance and with sensitivity to her concerns. After debating and clarifying her future plans, we both reached the same conclusion; she did not have the devotion nor the conviction to dedicate her life as a nun. To reach that conclusion was an enormous relief for Nancy. Having reached that conclusion, the next question was; how does she inform her parents, her family, her friends, and Anita of her decision? To understand Nancy's struggle, we must comprehend that she feared how her parents and extended family would react to her new decision. As a young Latino woman, she was immersed in the cultural value of familismo, where family is not only the primary support, but it also influences individual actions and decisions. Their possible disapproval could potentially be devastating to Nancy.

The next three sessions were dedicated to making a plan for how to inform all her significant others of her new decision. We initially explored her assertiveness skills. It was evident that she became very nervous in various role-playing where she practiced how to inform her decision, without hesitation and in a convincing way. We utilized various behavioral techniques (e.g., feedback, modeling, and role-playing) with the aim of helping Nancy with her communication and assertiveness skills. At the end of those three sessions, Nancy could explain in a convincing way her reasons for abandoning her pledge to become a nun. Nancy was now fully convinced that she did not want to become a nun and, furthermore, that she had the confidence to patiently explain her newfound reasons to her family, friends, and people of her religious congregation.

She was going to explain that when she took the pledge, she was socially and emotionally immature. Now, at the age of 21 , she has discovered other interests and has had experiences that estranged her from her previous commitment to a nun's life. Now, she wanted to explore a romantic relationship and to eventually have children. Also, she wanted to continue her graduate studies and to travel the world,.

Nancy progressed enormously from a confused and conflicted mental state to one that could be described as centered on her needs and aspirations. The next step was to identify the first person that would receive the news. By her reasons, she decided to begin with her father and mother.

In the next session, Nancy began telling me that she was happy and relaxed. When she utilized her assertiveness skills and told her parents about her decision, both of them were supportive and both expressed that the most important thing was her mental and emotional health. She immediately sensed an enormous emotional relief. Gone were the days when she thought that her parents would show a deep disappointment in her. 
Two days later, she phoned some of her best female friends and shared with them her decision. All of them, without exception, were supportive and two of them even revealed that they always thought that she would be unhappy as a nun. One of them told her: "You are so pretty, sexy, intelligent, and adventurous that I could not conceive of you living as a nun."

Another person that she called was Anita; the nun that would likely be mentoring her at the convent. Cautiously she explained to Anita that she was having many doubts and that she could not make a commitment under those circumstances. To her surprise, Anita also was supportive and told Nancy to take her time and to remain in touch in case she reconsidered her decision. Days later, she began to call leaders and friends in her religious community and informed them of her change of mind. Although many were surprised, most of them were supportive.

With my help, Nancy had become aware of her reasons to be afraid and conflicted, reappraised her expectations for the future, and made new decisions. She had then taken the crucial step of earning her family and friends commitment to her new future.

\section{WHY DOES PNES COME AND GO?}

Prior to psychotherapy, Nancy was experiencing extreme doubts and fears about her decision to become a nun, as well as, about the consequences of changing her mind. I hypothesized that PNES was manifestation of Nancy's powerlessness and helplessness about coping with grave danger, her impasse between living an unauthentic life in the convent, and the risk of rejection by her current community.

When she began psychotherapy, Nancy's PNES remained unabated: about 15 per month. In fact, the PNES were interfering with her studies and work. But then, when she deliberated her conflicts and became certain of wanting fulfillment in a lay person's roles, like a wife and a mother, her seizures dramatically diminished. Five weeks after initiating psychotherapy, she was reporting only a single episode per week. When she finally decided to inform her parents and other significant others of her new decision, the episodes of PNES diminished more to two in a month, compared to 30 just two months earlier.

\section{NANCY'S NEW LIFESTYLE}

Nancy decided to continue the psychotherapy sessions, but only once a month. She wanted to consult and reflect on the new challenges that were born of her new lifestyle. For example, a month after telling all those concerned about her decision, she decided to begin dating. She dated a man call "Juan" (a pseudonym), but decided to finish the relationship because 
he was, in her opinion, too "machista," meaning an exaggerated sense of traditional masculinity. Then, she began to date "Elvin" (a pseudonym), who was eight years her senior. Elvin was handsome, single, a lawyer, and was economically stable. Additionally, when she told him of her sporadic PNES, he showed a supportive attitude.

In this phase, my stance, as Nancy's therapist, was to help her establish new life goals and then fulfill those (Tryon \& Winograd, 2011). My contribution was to advise Nancy about choosing life goals congruently with her capacity to be aware of her thoughts and feelings and to share them without fear. As she was a young Latino woman, I also advised Nancy to remain aware of her Latino values, such as familismo and respeto for her elders.

In the next four sessions, Nancy spoke of her new lifestyle and revealed that she felt more congruent, meaning that she had developed the capacity to own and express thoughts and feelings without fear. Furthermore, her relationship with Elvin was progressing in a satisfactory way. In the last four months, she had only three PNES of short duration. This reduction is very significant. Studies have shown that PNES is recalcitrant to traditional treatments. Even those proven effective in other disorders, e.g., cognitive behavioral therapy, rarely produce full remission with PNES. In one study, (Goldstein, Deale, Mitchell, Toone and Mellers, 2004) mean seizure frequency fell from 18 per month to three per month at the end of treatment. At the 6-month follow up, only four of 16 treatment completers had been seizure-free. Replicating those findings, Nancy's seizure frequency of seizures fell gradually in the early stages of treatment. My explanation is that her conflict and fears occasionally resurged in intensity and created the conditions for coping with somatoform dissociation.

In our final session, Nancy told me that in the last four weeks she had experienced no PNES and that she thought that we could end the psychotherapy. I agreed with her. Two months later, a follow-up phone conversation revealed that she has not experienced any PNES and that her relationship with Elvin was going well. It was obvious that Nancy felt more confident in her decisions and in the fact that she could find solutions to her problems and dilemmas. Additionally, as the PNES abated, she could resume without fear or anxiety many of her life tasks.

\section{CONCEPTUALIZATION OF NANCY'S CASE}

The typical PNES patient presents with history of trauma, recurrent stressful situations, and conflict in interpersonal relationships (Bowman, 2006, 2010). In the case of Nancy, I noted her conflict about defining her spiritual or religious life. According to Pargament's studies (Pargament, Murray-Swank, Magyar \& Ano, 2005; Pargament, Koenig, Tarakeshwar \& 
Hahn, 2001), a significant number of religious persons encounter spiritual struggles at some point in their life. Pargament (2006) has noted that such struggles manifest in several domains, including intrapersonal, interpersonal, and in relation with the divine. The first refers to a person's own spiritual uncertainties, e.g., about the value of sex or of chastity. Interpersonal spiritual struggles arise when a person's preferences come into conflict with the expectations of a religious congregation, friends, or family. Struggle with the divine arises from uncertainty about God's laws themselves. Nancy's spiritual struggles were in the intrapersonal and interpersonal domains.

The empirical literature about the psychological effects of spiritual struggles shows that those conflicts lead to depression, anxiety, and dissatisfaction with life goals (Exline \& Rose, 2013). I should mention remarks about the various meanings of psychogenic seizures by Bowman (2006), who has extensive clinical experience with PNES. I quote: "I have observed many conversion seizure episodes provoked by discussion of past trauma or of the current life situation or emotional conflict that the seizure express" (p. 198). Similarly, Van der Kolk (2014) has pointed out that individuals who are failing to cope with traumatic or otherwise stressful events may express their suffering with substitutive actions: unexplained somatic symptoms or somatoform dissociation. I searched the clinical and empirical literature for studies of somatoform dissociation in the course of spiritual struggles, but I could not find one. Thus, the present case study introduces the observation of a person who used dissociative defenses while suffering such a struggle. In the case of Nancy, seizures were outward expression of her fear that her religious congregation and family would treat renouncing her earlier commitment as betrayal.

My psychotherapeutic approach for Nancy was very similar to that proposed by Howlett and Reuber (2009) for the treatment of PNES. They call their approach psychodynamic interpersonal therapy. In that approach, the therapist first uses an emphatic and collaborative stance to explore how conflict in significant relationships might be connected with the patient's symptoms. The therapist and the patient formulate clinical hypotheses where both explore reasons and emotions that might underlie the patient's symptoms. In the case of Nancy, we collaboratively identified and transformed her impasse of reasons and emotions. She was able then to end her struggle and present her aspirations to significant people without guilt.

As Nancy took those steps with growing confidence, PNES began to abate in a remarkable way. The "new" Nancy, with a clear view of the life she wanted, able to assert herself and confident that she earned others' support, no longer needed dissociative somatoform symptoms. Now, free from deep conflict and grave fear, Nancy opened the door for an authentic and meaningful life. 


\section{REFERENCES}

Barry, J. J. (2006). Hypnosis and psychogenic movement disorders. In M. Hallett, S. Fahn, J. Jankovic, A. Lang, R. Cloninger \& S. Yudofsky (Eds.), Psychogenic Movement Disorders (pp. 241-248). Philadelphia: Lippincott, Williams \& Wilkins.

Bodde, N. M. G., Van der Kruijs, S. J. M., Ijff, D. M., Lazeron, R. H. C., Vonck, K.E.J., Boon, P., \& Aldenkamp, A. P. (2013). Subgroup classification in patients with psychogenic non-epileptic seizures. Epilepsy and Behavior, 26, 279-289.

Bowman, E. S. (2006). Why conversion seizures should be classified as a dissociative disorder. Psychiatric Clinics of North America, 29, 185-212.

Bowman, E. S. (2010). Posttraumatic stress disorder, abuse, and trauma: Relationship to psychogenic nonepileptic seizures. In W. C. LaFrance \& S. C. Schachter (Eds.), Gates and Rowan's nonepileptic seizures (pp. 213-224). New York: Cambridge University Press.

Brown, R. J., Cardeña, E., Nijenhuis, E., Sar, V., \& Van der Hart, O. (2007). Should conversion disorder be reclassified as a dissociative disorder in DSM-V? Psychosomatics, 48, 369-378.

Ellenberger, H. (1970). The discovery of the Unconscious. New York: Basic Books.

Exline, J. J., \& Rose, E. D. (2013). Religious and spiritual struggles. In R. F. Paloutzian \& C. L. Park (Eds.), Handbook of the Psychology of Religion and Spirituality (pp. 380-398). New York: Guilford Press.

Falicov, C. J. (2014). Latino families in Therapy. New York: Guilford Press.

Goldstein, L. H., Deale, A.C., Mitchell, S. J., Toone, B. K., \& Mellers, J. D. (2004). An evaluation of cognitive behavioral therapy as a treatment for dissociative seizures. Cognitive and Behavioral Neurology. 17, 41-49.

González-Vázquez, A. I., Río-Casanova, L., Seijo-Ameneiros, N., CabaleiroFernández, P., Seoane-Pillado, T., Justo-Alonso, A., \& Sanyed-Germán, M.A. (2017). Validity and reliability of the Spanish version of the Somatoform Dissociation Questionnaire (SDQ- 20). Psicothema, 29, 275-280.

Howlett, S., \& Reuber, M. (2009). An augmented model of brief psychodynamic interpersonal therapy for patients with nonepileptic seizures. Psychotherapy, $46,125-138$.

LaFrance, W. C., \& Schachter, S. C. (Eds.) (2018). Gates and Rowan's Nonepileptic Seizures. New York: Cambridge University Press.

Martínez-Taboas, A. (2002). The role of hypnosis in the detection of psychogenic seizures. American Journal of Clinical Hypnosis, 45, 11-20.

Moene, F. C., \& Kuyk, J. (2010). Hypnosis in the treatment for psychogenic nonepileptic seizures. In W. C. LaFrance \& S. C. Schachter (Eds.), Gates and Rowan's nonepileptic seizures (pp. 297-306). New York: Cambridge University Press.

Nijenhuis, E. R. S., Van der Hart, O., Kruger, K., \& Steele, K. (2004). Somatoform dissociation, reported abuse and animal defence-like reactions. Australian and New Zealand Journal of Psychiatry, 38, 678-686.

Nijenhuis, E. R. S. (2009). Somatoform dissociation and somatoform dissociative disorder. In P. F. Dell \& J. A. O'Neil (Eds.), Dissociation and the dissociative disorders: DSM-V and beyond (pp. 259-276). New York: Routledge. 
Nijenhuis, E. R. S., Spinhoven, P., Van Dyck, R., an der Hart, O., \& Vanderlinden, J. (1996). The development and the psychometric characteristics of the Somatoform Dissociation Questionnaire (SDQ-20). Journal of Nervous and Mental Disease, 184, 688-694.

Pargament, K. I., Desai, K., \& McConnell, K. M. (2006). Spirituality: A pathway to posttraumatic growth or decline? In L. G. Calhoun \& R. G. Tedeschi (Eds.), Handbook of posttraumatic growth: Research and practice (pp. 121-137). Mahwah, NJ: Lawrence Erlbaum Publishers.

Pargament, K. I., Murray-Swack, N., Magyar, G. M., \& Ano, G. G. (2005). Spiritual struggle: A phenomenon of interest to psychology and religion. In W. R. Miller \& H. Delaney (Eds.), Judeo- Christian perspectives on psychology: Human nature, motivation, and change (pp. 245-268). Washington, DC: American Psychological Association.

Pargament, K. I., Koenig, H. G., Tarakeshwar, N., \& Hahn, J. (2001). Religious struggle as a predictor of mortality among the medically ill elderly patients: A two-year longitudinal study. Archives of Internal Medicine, 161, 1881-1885.

Pick, S., Mellers, J., \& Goldstein, L. H. (2017). Dissociation in patients with dissociative seizures: Relationships with trauma and seizure symptoms. Psychological Medicine, 47, 1215-1229.

Sar, V., Akyuz, G., Kundakci, T., Kiziltan, E., \& Dogan, O. (2004). Childhood trauma, dissociation, and psychiatric comorbidity in patients with conversion disorder. American Journal of Psychiatry, 161, 2271-2276.

Trimble, M. (2010). Psychogenic nonepileptic seizures: Historical overview. In S. C. Schachter \& W. C. LaFrance (Eds.), Gates and Rowan's nonepileptic seizures (pp. 17-26). New York: Cambridge University Press.

Tryon, G. S., \& Winograd, G. (2011). Goal consensus and collaboration. In J. C. Norcross (Ed.), Psychotherapy relationships that work (pp. 153-167). New York: Oxford University Press.

Van der Kolk, B. (2014). The body keeps the score. New York: Viking.

Yaila, S., Bakim, B., Tankaya, O., Ozer, O. A., Karamuztafalioglu, O., Ertekin, H., \& Tekin, A. (2015). Psychiatric comorbidity in patients with conversion disorder and prevalence of dissociative symptoms. Journal of Trauma and Dissociation, 16, 29-38. 